\title{
Pengelolaan Anestesi pada Pasien yang dilakukan Eksisi Tumor Medula Spinalis Servikal 2-3 dengan Ventrikel Ekstra Sistole
}

\author{
Nurmala Dewi Maharani"), Iwan Abdul Rachman ${ }^{* * *}$, Dewi Yulianti Bisri**), Sudadi ${ }^{* * *}$, Siti Chasnak Saleh $\left.{ }^{* * * *}\right)$ \\ *Departemen Anestesiologi dan Terapi Intensif Fakultas Kedokteran Universitas Sriwijaya- RSUP Mohammad \\ Hoesin Pelembang, ${ }^{* *}$ Departemen Anestesiologi dan Terapi Intensif Fakultas Kedokteran Universitas Padjadjaran \\ RSUP Dr. Hasan sadikin Bandung, ${ }^{* * *}$ Departemen Anestesiologi dan Terapi Intensif Fakultas Kedokteran \\ Universitas Gadjah Mada-RSUP Dr. Sardjito Yogyakarta, ${ }^{* * * *}$ Departemen Anestesiologi dan Terapi Intensif \\ Fakultas Kedokteran Universitas Airlangga-RSUD Dr. Soetomo Surabaya
}

\begin{abstract}
Abstrak
Penyakit yang mengakibatkan kompresi medulla spinalis dapat mengakibatkan iritasi pada sistem saraf otonom. Hiperinervasi saraf simpatis berisiko tinggi pada aritmia ditandai adanya perubahan pada elektrokardiografi, yakni perubahan durasi gelombang P, durasi QRS, depresi segmen ST, interval puncak gelombang T dan ventrikel ekstrasistol. Laki- laki 52 tahun dengan tumor intra-ektramedullar pada area cervikalis 2-3 dengan tetraparesis dan ventrikel ektrasistol dilakukan wide eksisi tumor dan stabilisasi posterior. Pemeriksaan fisik nadi $90 \mathrm{x} / \mathrm{menit}$ teraba tidak teratur. Elektrokardiogarfi (EKG) didapatkan hasil irama irreguler $82 \mathrm{x} / \mathrm{menit}$, ventrikel ektrasistol $10 \mathrm{x} /$ menit. Echocardiography menunjukkan disfungsi diastolik grade 3 preserved LV function. Sebelum operasi pasien diberikan terapi ventrikel ektrasistol dengan menggunakan analgetik dan amiodaron $150 \mathrm{mg}(10 \mathrm{~mL})$ pada 10 menit pertama, dilanjutkan dengan $360 \mathrm{mg}(200 \mathrm{mg})$ untuk 6 jam selanjutnya, $540 \mathrm{mg}$ untuk 18 jam berikutnya dan analgetik. Induksi anestesi dilakukan dengan midazolam 3 mg, fentanyl 200 mcg, lidokain 60 mg, propofol 100 $\mathrm{mg}$, dan atricurium $30 \mathrm{mg}$ serta intubasi manual in-line. Dilakukan pemasangan arteri line dan kateter vena sentral setelahnya pasien diposisikan prone. Pembedahan berlangsung 6 jam. Pasien dirawat di ICU 2 hari sebelum pindah ruang rawat biasa. Pemberian amiodarone sendiri dapat dipertimbangkan pada ventrikel ekstrasistol maligna yang memerlukan tatalaksana segera dengan pertimbangan hemodinamik pasien dalam keadaan stabil.
\end{abstract}

Kata kunci: anestesi, disritmia jantung, tumor medula spinalis, ventrikel ekstrasistol

JNI 2021; 10 (2): 91-101

\section{Anesthesia Management for Cervical 2-3 Spinal Cord Tumor with Ventricles Extrasystole}

\begin{abstract}
Compression of the spinal cord can cause irritation to the autonomic nervous system. Hyperinervation of sympathetic nerves at high risk for arrhythmias characterized by electrocardiographic results in changes in P-wave duration, QRS duration, ST-segment depression, T-wave peak interval, and ventricular extrasystole. A 52-year-old male with an intra-extramedullar tumor in cervical 2-3, tetraparesis, dysrhythmias, and ventricular extrasystole bigemini. Wide excision of tumor and posterior stabilization would be performed. The pulse was 90x/minute palpable irregularly. Electrocardiography examination revealed irregular rhythm $82 \mathrm{x} / \mathrm{minute}$ and ventricular extrasystole $10 \mathrm{x} /$ minute. Echocardiography showed grade 3 diastolic dysfunction with preserved LV function. Before the procedure, the patient was given management for the dysrhythmia and ventricular extrasystole with analgetics and amiodaron $150 \mathrm{mg}(10 \mathrm{ml})$ in the first 10 minutes followed by $360 \mathrm{mg}(200 \mathrm{mg})$ for the next 6 hours, 540mg for the next 18 hours and analgetics. General anesthesia carried out with midazolam $3 \mathrm{mg}$, fentanyl 200mcg, lidocaine $60 \mathrm{mg}$, propofol 100mg, and atricurium 30mg, with manual intubation in-line. After arterial line and central venous catheter insertion, the patient was placed in the prone position. Surgery lasted for approximately 6 hours. The patient was treated in the ICU for 2 days before moving to the usual ward. Amiodarone can be considered in ventricular extrasystole requiring immediate treatment with stable hemodynamic.
\end{abstract}

Key words: anesthesia, cardiac dysrhythmias, spinal cord tumors, extrasystole ventricl

JNI 2021; 10 (2): 91-101

This article is licensed under a

Creative Commons Attribution-NonCommercial-ShareAlike 4.0 International License.

ONurmala D. Maharani, Iwan Abdul R, Dewi Yulianti B, Sudadai, siti C Shaleh

(2021) under the CC-BY-NC-SA license 


\section{Pendahuluan}

Tumor primer vertebrae merupakan tumor yang jarang dan hanya sekitar 5\% dari keseluruhan tumor medulla spinalis. Dalam penegakan diagnosis, pencitraan radiologis sangat bermanfaat. Untuk pendekatan diagnosis tumor spinal, berdasarkan anatominya klasifikasi tumor dibagi menjadi ekstradural, ekstramedullar intradural, dan intramedullar. Tumor ekstramedulla intradural terjadi pada $40 \%$ tumor spinal dan berlokasi di dalam dura, namun diluar medulla spinalis. Tumor yang berkembang di dalam ruang ini biasanya jinak, dan lebih dari $90 \%$ nya berupa tumor selubung saraf atau meningioma. Tumor selubung saraf ini dapat berlokasi di sisi manapun dari tulang belakang dan biasanya berupa meningioma, ependimoma, neurofibroma atau schwannoma, yang cenderung berlokasi di dorsal atau serabut saraf sensoris. Defisit neurologis dapat bervariasi mulai dari gejala radikular ringan sampai disfungsi medulla spinalis. Defisit neurologis dapat terjadi sebagai respons terhadap fraktur patologis vertebrae atau dislokasi tubuh atau kompresi saraf progresif dari pertumbuhan tumor, efek dari tumor pada stabilitas biomekanik tulang belakang, dan keterlibatan jaringan sekitarnya. ${ }^{1,2}$

Operasi tulang belakang pada servikal dapat menyebabkan berbagai efek fisiologis sebagai akibat dari ketidakstabilan tulang belakang, seperti efek pada sistem kardiovaskular, respirasi, neurologis, urogenital dan gastrointestinal. Pemahaman pada cedera medulla spinalis primer dan menghindari terjadinya cedera sekunder merupakan prinsip pengelolaan neuroanestesi pada operasi tulang belakang. Pada sistem kardiovaskular perspektif kejadian ini berhubungan dengan jantung dan status hemodinamik akibat gangguan induksi sistem saraf otonom. Pada medulla spinalis terdapat ganglia servikal yang terdiri dari paravertebra ganglia sistem saraf simpatis. Jantung dipersarafi oleh nervus vagus. Penyakit yang mengakibatkan kompresi kepada medulla spinalis dapat mengakibatkan iritasi pada sistem saraf otonom. Hiperinervasi pada saraf simpatis yang berisiko tinggi pada aritmia biasanya ditandai dengan adanya perubahan pada elektrokardiografi yaitu perubahan durasi gelombang $\mathrm{P}$ (depolarisasi atrium), durasi QRS (depolarisasi ventrikel), depresi segmen ST (periode isoelektrik antara depolarisasi dan repolarisasi ventrikel), Interval puncak gelombang $\mathrm{T}$ (repolarisasi ventrikel), dan ventrikel ekstrasistol. Insiden aritmia meningkatkan angka kejadian komplikasi berupa atrial fibrilasi, ventrikel takikardia, supraventrikular takikardia. ${ }^{3}$

Efek fisiologis pada medulla spinalis cervikalsi yang paling jelas adalah terjadinya ketidakstabilan kardiovaskular, disritmia jantung, dan disfungsi ventrikel, sedangkan apabila di bawah T5 menghasilkan berbagai tingkat hipotensi yang disebabkan oleh simpatektomi fungsional di bawah tingkat cedera. Hipotensi sendiri didefinisikan sebagai tekanan darah sistolik di bawah $90 \mathrm{~mm} \mathrm{Hg}$ atau penurunan 30\% tekanan darah sistolik. Untuk mencegah cedera sekunder medulla spinalis dianjurkan bahwa tekanan arteri rata-rata dipertahankan pada $\geq 85 \mathrm{~mm} \mathrm{Hg}$ selama 7 hari pertama intraoperatif. Dikarenakan hilangnya autoregulasi akibat manipulasi medulla spinalis, maka penggunaan cairan secara bijaksana dan obat vasoaktif sangat penting untuk mengoreksi hipotensi dan menjaga fungsi neurologis yang optimal. Ketika menggunakan vasopresor untuk mengobati hipotensi pada pasien dengan syok neurogenik, agen agonis $\alpha$-agonis intravena (norepinefrin dan fenilefrin) adalah agen pilihan. Pemantauan hemodinamik invasif direkomendasikan untuk memandu hipotensi persisten dalam syok neurogenik. ${ }^{1,4}$ Tiga pendekatan bedah dasar digunakan untuk mengobati cedera vertebra: anterior, posterior, atau kombinasi dari dua metode tersebut. Stabilisasi bedah posterior diindikasikan untuk gangguan signifikan pada tulang posterior atau struktur ligamen tulang servikal. Anestesi dengan posisi prone mengakibatkan perubahan fisiologis pada sistem kardiovaskular dan respirasi. Penurunan stroke volume akibat kompresi vena cava inferior menyebabkan penurunan preload. Oleh sebab itu, kita perlu memahami perubahan fisiologis dan pemahaman yang baik akan masalah posisi prone ini. ${ }^{1,5}$ 


\section{Kasus}

Pasien laki- laki berusia 52 tahun, didiagnosis dengan tumor intra-ekstramedullar pada C2-3 disertai tetraparesis dan ventrikel ekstrasistol maligna, akan dilakukan wide eksisi tumor dan stabilisasi posterior.

\section{Anamnesa:}

Pasien mengeluh adanya benjolan pada leher sekitar 1 tahun terakhir. Benjolan tersebut disertai rasa nyeri pada leher tersebut jika digerakkan. Pasien mengeluh kelemahan keempat anggota gerak pada tangan hingga kaki yang diikuti rasa kebas. Mual muntah dan demam disangkal. Riwayat trauma, hipertensi, diabetes melitus disangkal.

\section{Pemeriksaan Fisik}

Pada pemeriksaan prabedah didapatkan pasien dengan kondisi jalan nafas bebas, dengan pernafasan spontan torakal adekuat 16x/menit, gerak dada simetris, suara nafas vesikuler kanan dan kiri, dan tidak terdapat suara nafas tambahan. Pulse oximetry terbaca $97 \%$ dengan $\mathrm{O}_{2}$ udara bebas $\left(\mathrm{FiO}_{2} 21 \%\right)$. Pada perabaan didapatkan perfusi hangat kering dan merah dengan capillary refill time kurang dari 2 detik. Tekanan darah 130/80 mmHg dan nadi $90 \mathrm{x} / \mathrm{menit}$, nadi radialis teraba tidak teratur dan kuat angkat. Skor GCS E4M5V6, pupil bulat isokor diameter $3 \mathrm{~mm}$ dengan refleks cahaya positif kanan dan kiri. Pada pemeriksaan fisik terdapat benjolan di sekitar leher kiri. Pada pemeriksaan kekuatan motorik setinggi C8 didapatkan 3/3, sedangkan fungsi

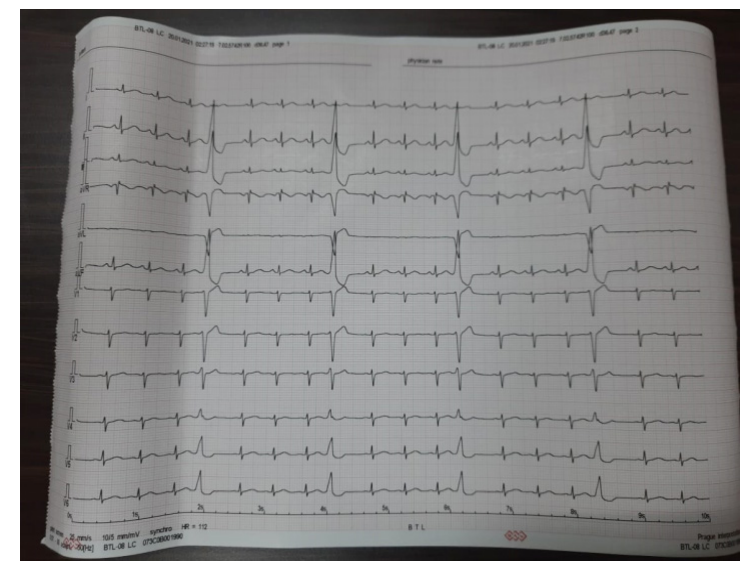

Gambar 1. EKG preoperatif didapatkan ventrikel ekstrasistol

sensorik menurun dari antebrachii sampai pedis. Pada pasien ini tidak didapatkan inkontinensia urin dan inkontinensia alvi.

\section{Pemeriksaan Penunjang}

Pada pemeriksaan darah $\mathrm{Hb}$ 15,6 leukosit, 4700, trombosit 341.000, PT 13,8, INR 1,02 APTT 29,9 , GDS 107 , ureum 17 , kreatinin 0,70, natrium 136, kalium, 3,7. Analisa gas darah $\mathrm{PH} 7.390$ $\mathrm{PCO}_{2} 34,8, \mathrm{PO}_{2} 156, \mathrm{HCO}_{3} 21, \mathrm{BE} 0.3, \mathrm{SaO}_{2}$ $99 \%$. Dari pemeriksaan foto toraks didapatkan

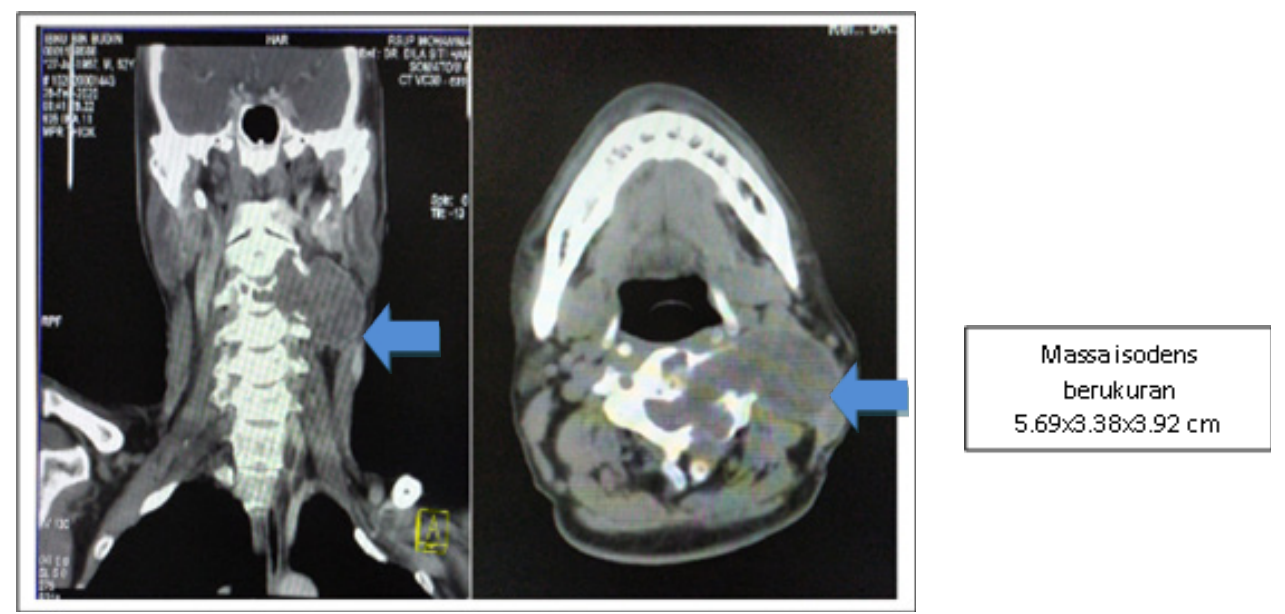

Gambar 2. CT scan cervical didapatkan di intracanalis spinalis setinggi C2-3 dan mendesak medula spinalis, serta mendestruksi corpus vertebra C3. 
cor prominen dengan Cardio Thoracic Ratio (CTR) $50 \%$ dan paru dalam batas normal. Dari pemeriksaan elektrokardiografi (EKG) didapatkan hasil irama irreguler $82 \mathrm{x} /$ menit, VES $10 \mathrm{x} /$ menit. Hasil echo wall motion normal, chamber normal, disfungsi diastolik grade 3 katup normal EF $61 \%$. Kesan echo disfungsi diastolik grade 3 preserved LV function. Berikut gambaran EKG preoperatif pasien.

\section{Penilaian}

Tumor intra-ektra medulla spinalis setinggi cervikal 2-3 dan ventrikel ekstrasistol maligna.

\section{Rencana Tindakan}

- Informed Concent

- Oksigenasi Nasal kanul 2 liter/menit

- Analgetik ketorolak $30 \mathrm{mg}$ tiap 8 jam dan tramadol $100 \mathrm{mg}$ tiap 8 jam

- Stabilisasi irama jantung amiodaron $150 \mathrm{mg}(10 \mathrm{~mL})$ pada 10 menit pertama dilanjutkan dengan $360 \mathrm{mg}(200 \mathrm{mg}$ ) untuk 6 jam selanjutnya, $540 \mathrm{mg}$ untuk 18 jam berikutnya. Pasien dimonitoring ekg selama 72 jam, gambaran ekg mengalami perbaikan, ventrikel ekstrasistol $<3 \mathrm{x} /$ menit.

- Operasi wide eksisi tumor dan stabilisasi posterior

- Pemantauan perawatan di ICU paskaoperasi

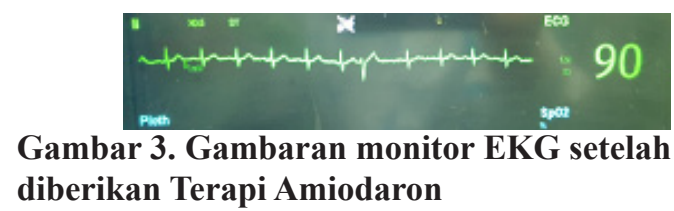

\section{Pengelolaan Anestesi}

Selama persiapan untuk pembedahan elektif, pasien dipuasakan dan diberikan cairan infus berupa kristaloid $80 \mathrm{cc} / \mathrm{jam}$. Kondisi pasien sebelum induksi anestesi adalah tekanan darah 130/90 mmHg, MAP $103 \mathrm{mmHg}$ dengan nadi $100 \mathrm{x} /$ menit irreguler kuat angkat dan tidak ditemukan VES lagi. Skor GCS E4M5V6 dengan pupil bulat isokor diameter $3 \mathrm{~mm}$ mata kanan dan kiri. Pasien tanpa distress nafas dengan saturasi oksigen $99 \%$ tanpa suplemen oksigen. Sebelum masuk kamar operasi, dilakukan pemeriksaan GDS 120. pasien diberi premedikasi midazolam
$2 \mathrm{mg}$ intravena. Induksi dilakukan dengan obatobatan anestesi sebagai berikut midazolam $3 \mathrm{mg}$ fentanyl $200 \mathrm{mcg}$, lidokain $60 \mathrm{mg}$, propofol 100 $\mathrm{mg}$ dan atracurium $30 \mathrm{mg}$ intravena kemudian dilakukan laringoskopi dan intubasi dengan pipa endotrakea nonkinking ukuran 7,5 dan difiksasi.

Selama pembedahan dilakukan rumatan propofol 75-200 mg/jam. Kemudian dilakukan persiapan pemasangan arteri line dan kateter vena sentral, setelahnya pasien diposisikan prone. Pada awal pembedahan wide ekisi luas massa extradura, dilakukan pemasangan lateral mass screw di vertebra C 2-3 dan dilakukan total laminektomi pada vertebra $\mathrm{C} 2-3$. Setelah dilakukan insisi arachnoidmeter, dilakukan identifikasi midline myelum dan dilakukan insisi. Tampak massa kemerahan, dilakukan diseksi tumor dan dipisahkan dari myelum. Dilakukan identifikasi pole atas dan bawah tumor kemudian ditutup. Tekanan darah intraoperatif berkisar 85-140/40$90 \mathrm{mmHg}$ dengan MAP 75-100 mmHg. Nadi berkisar antara $70-110 \mathrm{x} /$ menit reguler dengan VES kurang dari $5 \mathrm{x} /$ menit dan saturasi oksigen $100 \%$. Pada 2 jam pembedahan terjadi fase syok

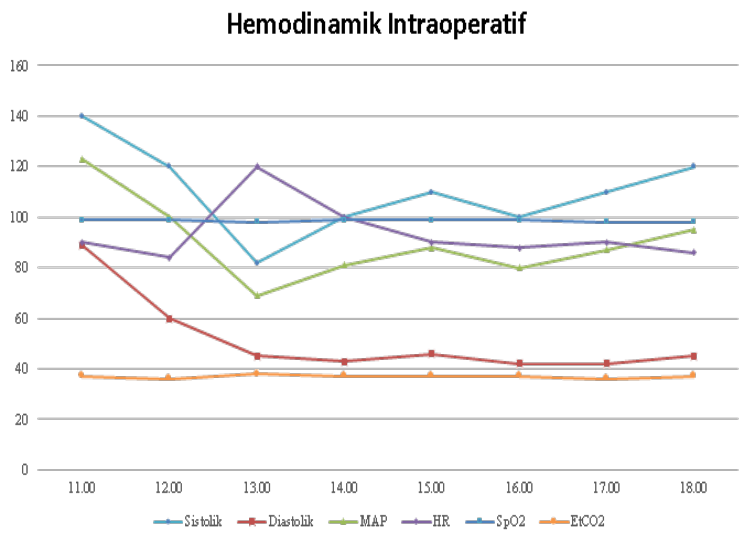

Gambar 4. Grafik hemodinamik intraoperatif

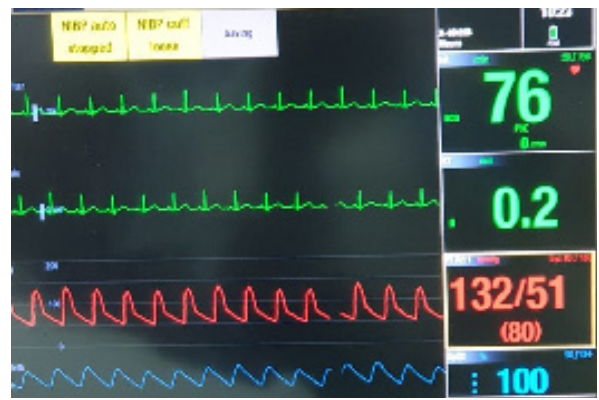

Gambar 5. Monitoring Intraoperatif 
yang dikoreksi dengan keseimbangan cairan dan penggunaan vasopresor norepinefrin di $0,1 \mathrm{mcg} /$ $\mathrm{kgbb} / \mathrm{jam}$. Pembedahan berlangsung kurang lebih selama 6 jam dengan keseimbangan cairan yaitu Ringer Laktat 1500 ml, Gelofusin 1000 ml, PRC $600 \mathrm{ml}$. Perkiraan perdarahan $2000 \mathrm{ml}$. Produksi urin selama pembedahan $500 \mathrm{ml}$.

Pengelolaan Pascabedah

Pascaoperasi pasien diobservasi di ICU dengan

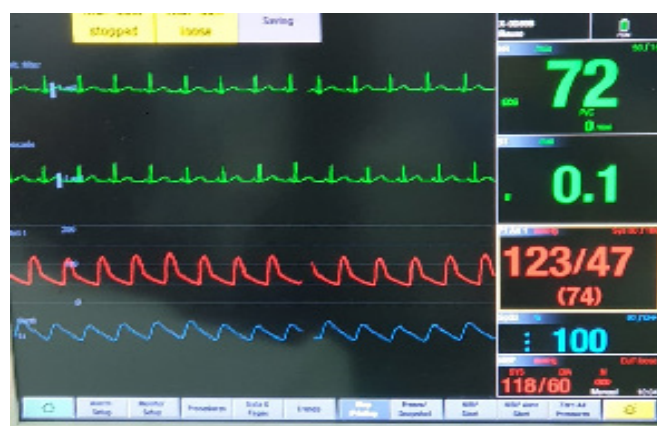

Gambar 6. EKG Postoperatif Perawatan di ICU

Tabel 1. Pengelolaan Pascabedah di Ruang ICU

\begin{tabular}{|c|c|c|c|}
\hline Hari & Klinis & Laboratorium & Terapi \\
\hline $\mathrm{H}-0$ & & $\mathrm{Hb} 10.0$ & \\
\hline 14.00 & 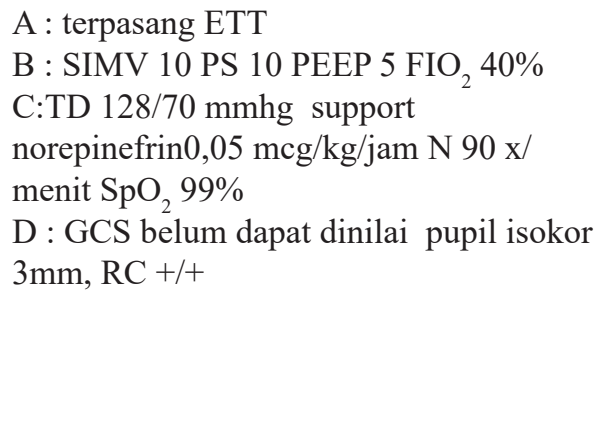 & $\begin{array}{l}\text { Leukosit } 12.500 \\
\text { Trombosit } \\
171.000 \\
\text { PT } 18 \\
\text { INR } 1.36 \\
\text { APTT } 32.6 \\
\text { Na } 132 \\
\text { K } 4.1 \\
\text { Ca } 8.4 \\
\text { Alb } 3.1\end{array}$ & $\begin{array}{l}\text { Ceftriaxon } 1 \times 2 \text { gram } \\
\text { Dexmedetomidine } \\
0.2 \mathrm{mcg} / \mathrm{kg} / \mathrm{jam} \\
\text { Morphine } 10 \mathrm{mcg} / \mathrm{kg} / \mathrm{jam} \\
\text { Omeprazole } 1 \text { x } 40 \mathrm{mg}\end{array}$ \\
\hline 17.00 & $\mathrm{~B}$ :SIMV 8 PS 10 PEEP $5 \mathrm{FIO}_{2} 40 \%$ & $\begin{array}{l}\mathrm{PH} 7.390 \\
\mathrm{PCO}_{2} 34.1 \\
\mathrm{PO}_{2} 209.1 \\
\mathrm{HCO}_{3} 20.8\end{array}$ & \\
\hline 20.00 & B : PS 10 PEEP $5 \mathrm{FIO}_{2} 40 \%$ & & \\
\hline $\begin{array}{l}\mathrm{H}-1 \\
07.00\end{array}$ & $\begin{array}{l}\text { A: Clear } \\
\text { B: PS } 8 \text { PEEP } 5 \mathrm{FIO}_{2} 40 \% \\
\text { C : TD } 128 / 70 \mathrm{mmhg}^{\mathrm{N}} 90 \text { x/menit VES } \\
\text { (-) } \mathrm{SpO}_{2} 99 \% \\
\text { D : E4M5VT pupil }\end{array}$ & $\begin{array}{l}\mathrm{PH} 7.36 \\
\mathrm{PCO}_{2} 35.7 \\
\mathrm{PO}_{2} 139.1 \\
\mathrm{HCO}_{3} 22\end{array}$ & $\begin{array}{l}\text { Ceftriaxon } 1 \times 2 \mathrm{gram} \\
\text { Morphine } 10 \mathrm{mcg} / \mathrm{kg} / \mathrm{jam} \\
\text { Omeprazole } 1 \text { x } 40 \mathrm{mg} \\
\text { Dexmedetomidine } \\
0.2 \mathrm{mcg} / \mathrm{kg} / \mathrm{jam}\end{array}$ \\
\hline 10.00 & $\begin{array}{l}\text { isokor } 3 \mathrm{~mm}, \mathrm{RC}+/+ \\
\mathrm{B} \text { : PS } 5 \text { PEEP } 5 \mathrm{FIO}_{2}\end{array}$ & & \\
\hline 12.00 & $\begin{array}{l}40 \% \\
\mathrm{~B}: \mathrm{CPAP}\end{array}$ & & \\
\hline 14.00 & $\begin{array}{l}\text { B : T piece } \\
\text { B : Ekstubasi }\end{array}$ & & \\
\hline 16.00 & $\begin{array}{l}\text { A: Clear } \\
\text { B: RR : } 18 x / \text { menit } \mathrm{SpO}_{2}\end{array}$ & & \\
\hline 18.00 & $\begin{array}{l}\text { C : TD 128/70 mmhg N } 90 \text { x/menit } \mathrm{SpO}_{2} \\
99 \% \\
\text { D : E4M6V5 pupil isokor } 3 \mathrm{~mm}, \mathrm{RC}+/+\end{array}$ & & \\
\hline
\end{tabular}

Keterangan: H-0: Hari pasien masuk ICU; H-1: Hari pertama setelah perawatan di ICU; A: Airway; B: Breathing; C: Circulation; D: Disability 
dukungan ventilator mekanik mode teknik mekanik SIMV 10 Volume Tidal $450 \mathrm{ml}$ PEEP 5, Fraksi oksigen 40\%. Pasien tersedasi degan dexmedetomidine dan diberikan analgetik morphine $10 \mathrm{mcg} / \mathrm{jam}$. Hemodinamik dalam perawatan tekanan darah berkisar 100-130/60$90 \mathrm{mmHg}$ dengan MAP $75-100 \mathrm{mmHg}$. Nadi berkisar antara $70-110 \mathrm{x} /$ menit irreguler dengan VES kurang dari $3 \mathrm{x} /$ menit.

\section{Pembahasan}

Pasien ini menjalani operasi tulang belakang preoperatifsehingga berbagaiperubahanfisiologis dan masalah medis akibat cedera medulla spinalis yang terjadi pada pasien ini perlu dipahami. ${ }^{1}$

\section{Sistem Respirasi}

Cedera diatas cervikalis 3 menyebabkan kelumpuhan otot pernapasan yang hampir komplit sehingga memerlukan bantuan nafas untuk mencegah hiperkapnia dan hipoksemia, sedangkan pada cedera dibawah cervikalis 3 , beban kerja pernapasan sangat tergantung pada kontribusi efektif dari diafragma. Tidak adanya fungsi otot interkostal yang terus-menerus dan otot-otot perut yang lumpuh dapat membatasi ekspirasi dan membatasi kemampuan batuk secara efektif. Pada kasus ini sendiri pasien mengalami cedera cervikalis $2-3$, namun demikian saat evaluasi preoperatif tidak ditemukan adanya keluhan sesak nafas atau pemeriksaan fisik seperti adanya kelumpuhan otot pernafasan, retraksi, ataupun perubahan pola nafas. Hasil pemeriksaan respirasi ini juga dilengkapi dengan pemeriksaaan analisa gas darah. ${ }^{1}$ Manipulasi operasi yang dilakukan pada segmen cervikalis 2-3 memerlukan dukungan ventilasi mekanik selama fase awal pascabedah. Oleh sebab itu setelah operasi pengangkatan tumor pada medulla spinalis cervikalis, pasien dirawat di ruang ICU dengan bantuan ventilasi mekanik pascabedah. ${ }^{1}$

\section{Sistem Kardiovaskuler}

Tumor spinal sendiri dapat menyebabkan ketidakstabilan kardiovaskular, disritmia jantung, dan disfungsi ventrikel, sehingga dalam tatalaksana hipotensi akibat syok spinal dianjurkan untuk mempertahankan tekanan arteri rata-rata dipertahankan pada $\geq 85 \mathrm{mmHg}$ selama 7 hari. Oleh karena hilangnya autoregulasi akibat manipulasi spinal, pemberian cairan harus dilakukan secara bijaksana dan obat vasoaktif juga sangat penting untuk mengoreksi hipotensi dan menjaga fungsi neurologis tetap optimal. Vasopresor yang bisa digunakan yaitu agen agonis $\alpha$-agonis intravena (norepinefrin dan fenilefrin). Pada kasus ini, terjadi syok saat dua jam pembedahan, sehingga dikoreksi

Tabel 2. Level Cedera Medula Spinalis dan Fungsi Respirasi yang Berkaitan

\begin{tabular}{|c|c|c|c|}
\hline $\begin{array}{l}\text { Level } \\
\text { Cedera }\end{array}$ & $\begin{array}{l}\text { Fungsi } \\
\text { Ventilasi }\end{array}$ & Batuk & Kesimpulan \\
\hline Diatas C-3 & 0 & 0 & $\begin{array}{l}\text { Paralisis diafragma dan otot aksesorius menghasilkan apneu, } \\
\text { ketergantugan terhadap ventilator }\end{array}$ \\
\hline$C-3-C-5$ & $0 \mathrm{sd}+$ & 0 & $\begin{array}{l}\text { Paralisis parsial sampai komplit; paralisis otot aksesorius, } \\
\text { reduksi volume paru dengan hipoksemia; atelektasis berulang, } \\
\text { dan pneumonia; ketergantungan ventilasi mekanik; kecenderun- } \\
\text { gan trakeostomi; beberapa pasien dapat di weaning dari ventilasi } \\
\text { mekanik }\end{array}$ \\
\hline C-5 -C-7 & $+\mathrm{sd}++$ & $+\mathrm{sd}++$ & $\begin{array}{l}\text { paralisis otot aksesorius, reduksi volume paru dengan hipok- } \\
\text { semia; atelektasis berulang, dan pneumonia; beberapa pasien } \\
\text { membutuhkan ventilasi mekanik; kemungkinan trakeostomi }\end{array}$ \\
\hline $\begin{array}{l}\text { Thorakal } \\
\text { tinggi }\end{array}$ & ++ & ++ & $\begin{array}{l}\text { Paralisis paralis otot aksesorius, reduksi volume paru dengan } \\
\text { atelektasis, dan pneumonia; mungkin membutuhkan ventilasi } \\
\text { mekanik. }\end{array}$ \\
\hline
\end{tabular}


Tabel 3. Ringkasan Masalah Medis Pasien Cedera Korda Spinalis Kronis ${ }^{1}$

\begin{tabular}{|c|c|c|}
\hline Sistem & Abnormalitas & Keterangan \\
\hline Kardiovaskular & $\begin{array}{l}\text { Hiperefleksia Otonom, Penurunan } \\
\text { Volume darah, Hipotensi orthostatik }\end{array}$ & $\begin{array}{l}\text { krisis hipertensi jika level cedera medula } \\
\text { spinalis diatas thorakal 5; Perubahan posisi } \\
\text { dan tekanan intratorakal menyebabkan } \\
\text { hipotensi }\end{array}$ \\
\hline Respirasi & $\begin{array}{l}\text { Kelemahan otot, menurunnya kontrol } \\
\text { pernapasan, menurunnya reflek batuk }\end{array}$ & $\begin{array}{l}\text { Pasien dicurigai pneumonia bakterialis dan } \\
\text { sulit untuk weaning dari ventilasi mekanik }\end{array}$ \\
\hline Muskulus & $\begin{array}{l}\text { Proliferasi reseptor acetilkolin, } \\
\text { spastisitas }\end{array}$ & Hiperkalemia akibat suksinilkolin \\
\hline Genitourinaria & $\begin{array}{l}\text { Infeksi saluran kemih berulang, } \\
\text { terganggunya pengosongan kandung } \\
\text { kemih }\end{array}$ & $\begin{array}{l}\text { Dapat mencetuskan insufisiensi ginjal, } \\
\text { pielonefritis, sepsis atau amiloidosis }\end{array}$ \\
\hline Gastrointestinal & Gastroparesis, ileus & Pasien dicurigai aspirasi \\
\hline Infeksius & pneumonia, ulkus decubitus, sepsis & Perhatikan tanda infeksi dan sepsis; \\
\hline Dermatologi & Ulkus dekubitus & $\begin{array}{l}\text { Perawatan kulit, bantalan busa untuk } \\
\text { tonjolan tulang, mobilisasi, }\end{array}$ \\
\hline Hematologi & $\begin{array}{l}\text { Anemia, risiko Deep Vein Thrombosis, } \\
\text { emboli paru }\end{array}$ & $\begin{array}{l}\text { Profilaksis DVT, Anti koagulan } \geq 3 \text { bulan, } \\
\text { jika DVT/Emboli paru }\end{array}$ \\
\hline Skeletal & Densitas tulang & $\begin{array}{l}\text { Osteoporosis, hiperkalsemia, osifikasi } \\
\text { heteropik, dan kalsifikasi muskulus }\end{array}$ \\
\hline $\begin{array}{l}\text { SSP (Sistem Saraf } \\
\text { Pusat) }\end{array}$ & $\begin{array}{l}\text { Nyeri post operasi, } \\
\text { Nyeri kronis }\end{array}$ & $\begin{array}{l}\text { Nyeri perioperatif sulit ditatalaksana, } \\
\text { sindroma nyeri kronis }\end{array}$ \\
\hline
\end{tabular}

dengan pembedahan cairan dan norepinefrin di $0,1 \mathrm{mcg} / \mathrm{kgbb} / \mathrm{jam}$ untuk mempertahankan tekanan arteri rata-rata $\geq 65 \mathrm{mmHg}$ dengan menggunakan akses vena sentral. Pemantauan hemodinamik invasif juga dilakukan dengan memasang arteri line selama intraoperatif untuk memantau terjadinya hipotensi atau syok. ${ }^{1}$ Hiperrefleksia autonomik terjadi pada $85 \%$ pasien dengan transeksi medulla spinalis di atas T5. Impuls aferen yang berasal dari stimulasi bedah ditransmisikan sepanjang saraf panggul, pudendal, atau hipogastrik ke medulla spinalis dan memberikan respons simpatik masif dari medulla adrenal dan simpatik sistem saraf, namun tidak lagi dimodulasi oleh inhibisi normal yang timbul dari batang otak dan hipotalamus. Vasokonstriksi yang terjadi di bawah lesi mengakibatkan aktivasi refleks baroreseptor karotis dan aorta. Vasodilatasi di atas lesi sering disertai dengan bradikardia dan disritmia ventrikel. Hiperinervasi pada saraf simpatis yang berisiko tinggi menyebabkan aritmia biasanya ditandai dengan perubahan hasil elektrokardiografi yaitu perubahan durasi gelombang $\mathrm{P}$, durasi
QRS, depresi segmen ST, interval puncak gelombang $\mathrm{T}$ dan ventrikel ekstrasistol. ${ }^{6-8}$ Aritmia merupakan perubahan mekanisme penjalaran impuls listrik jantung yang menyebabkan gangguan irama denyut jantung. Ventrikel Ekstrasistol adalah kelainan irama yang ditandai dengan timbulnya kompleks QRS lebar (LBBB atau RBBB) yang datang lebih awal dari pada interval irama dasarnya. Pada pemeriksaan fisik pasien ini ditemukan adanya laju nadi teraba ireguler dengan adanya pause kompensatoar. Pada pemeriksaan EKG pasien ini ditemukan VES jenis quadribigemini karena ditemukan ORS melebar ( $>0,12$ detik) yang datang lebih awal, kadang disertai pause kompensator setelah munculnya dua atau tiga kompleks QRS. Kriteria VES maligna yaitu $>6$ dalam 1 menit ( $10 \%$ dalam 24 jam, R on T, infark miokard, polimorfik, repetitive dan konsekutif (bigeminy, couplet, triplet, quadrigemini). Pada pasien ini dilakukan pemeriksaan echocardiography untuk menilai apakah ada kelainan struktural dan penurunan ejection fraction, sehingga pada pasien ini sebaiknya 
dilakukan pemerksaan holter monitoring untuk menilai berapa kali VES muncul dalam 24 jam dan untuk menentukan apakah tatalaksana cukup dengan medical treatment atau memerlukan tindakan ablasi ventrikel ekstrasistol. ${ }^{9-12}$ Tatalaksana ventrikel ekstrasistol dapat dilakukan dengan evaluasi nyeri. Analgetik yang ideal untuk pasien neuroanestesi tidak boleh menyebabkan depresi pernapasan maupun mempengaruhi tekanan intrakranial (TIK) dan cerebral perfusion pressure (CPP). Pada pasien ini diberikan ketorolak dan tramadol. Ketorolak bisa diberikan dengan batas dosis $<120 \mathrm{mg}$ /hari dikarenakan dosis tinggi (120-240 mg/hari) dan pemberian dalam jangka waktu lebih dari 3 hari dapat memicu gangguan dalam penyembuhan tulang, disfungsi platelet, risiko perdarahan, ulkus peptikum, dan toksik pada ginjal. Tramadol diberikan karena golongan opioid yang tidak memberikan efek depresi pernapasan dengan dosis $\quad 0.75 \mathrm{mg} / \mathrm{kg}$ dan $1.0 \mathrm{mg} / \mathrm{kg}$ intravena memberikan efek analgetik yang efektif untuk mengontrol nyeri pada pasien pascabedah. ${ }^{13,14}$ Amiodaron merupakan obat antiaritmia pilihan untuk ventrikel ekstrasistol karena dapat memblokir saluran ion kalium yang berperan dalam perpanjangan depolarisasi jantung, durasi potensial aksi yang ideal, dan periode refraktori yang efektif. Efek-efek ini bermanfaat dalam mencegah aritmia jantung dengan mengurangi proporsi siklus jantung selama sel-sel miokardial dieksitasi dan dengan demikian rentan terhadap peristiwa pemicu. Reentrant tachycardias dapat ditekan jika durasi potensial aksi lebih lama dari panjang siklus sirkuit takikardia. Amiodaron dapat diberikan dengan dosis awal $150 \mathrm{mg}$ selama 10 menit diulangi dengan dosis maintenance $1 \mathrm{mg} / \mathrm{menit}$ selama 6 jam dan 0,5 $\mathrm{mg} / \mathrm{menit}$ selama 18 jam (Gambar 7). Obat untuk tatalaksana aritmia kardiak tidak efektif dalam semua kondisi. Keuntungan obat antiaritmia akan lebih jelas terlihat ketika obat tersebut menyebabkan terminasi aritmia dengan segera dan menetap. Terapi takikardia supraventrikel dengan amiodarone menunjukkan keunggulan sebagai terapi antiaritmia pada kasus ini. ${ }^{9}$

\section{Sistem Gastrointestinal}

TAKIKARDIA PADA DEWASA

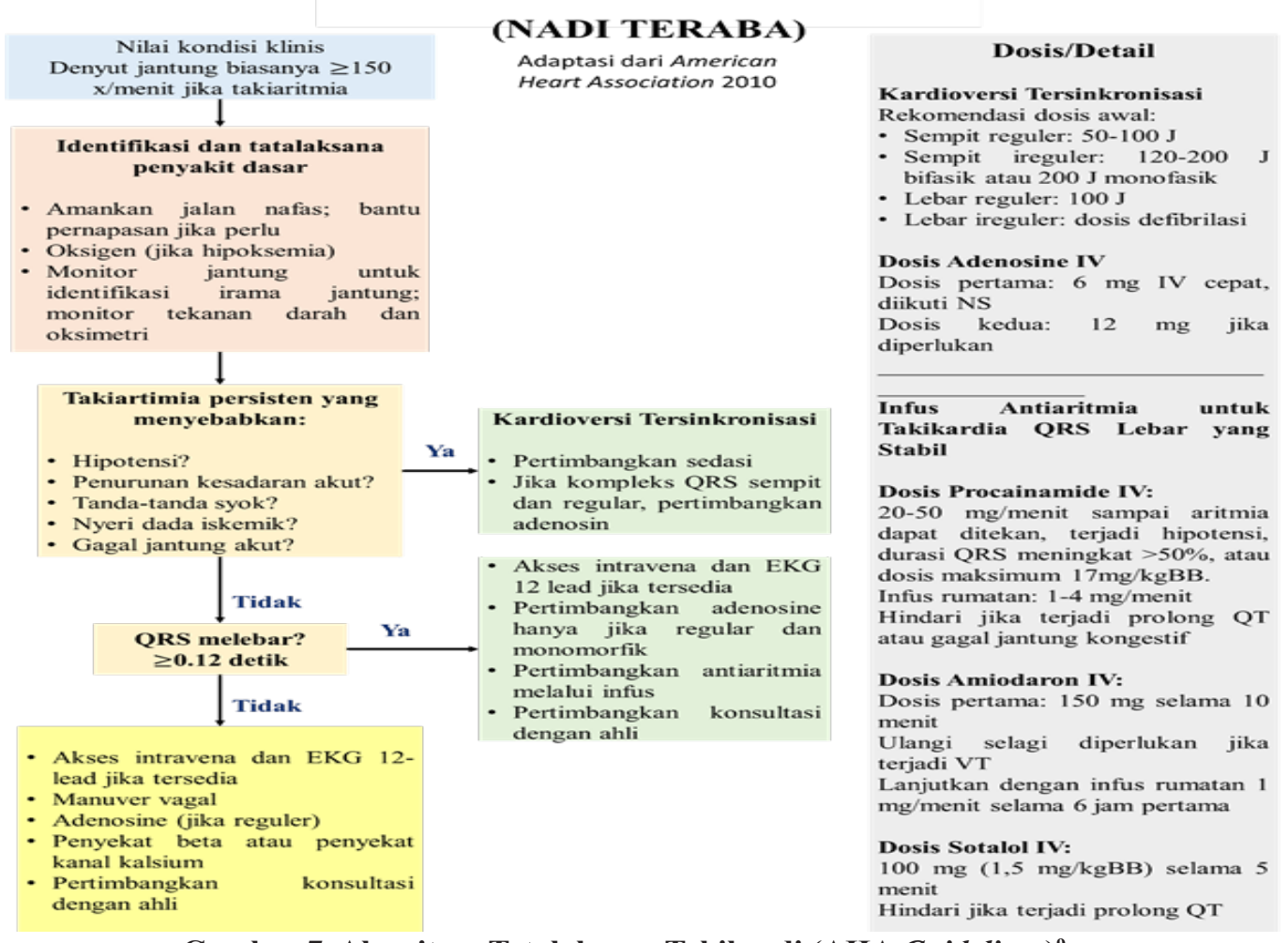

Gambar 7. Algoritma Tatalaksana Takikardi (AHA Guidelines) ${ }^{9}$ 
Pada intraoperatif dilakukan pemasangan dini tabung nasogastrik untuk membantu membatasi distensi dan mengurangi risiko regurgitasi. Pemasangan tabung nasogastrik juga dilakukan untuk meminimalkan efek buruk yang dapat terjadi pada diafragma dan sistem paru selama posisi pronasi intraoperatif maupun selama perawatan pascabedah di ICU menggunakan ventilator. ${ }^{1}$

\section{Sistem Genitourinari}

Pemasangan kateter dilakukan kepada pasien selama intraoperatif untuk memantau keseimbangan cairan selama perawatan. Kateter intraoperatif juga digunakan karena adanya risiko terganggunya pengosongan kandung kemih akibat lesi pada medulla spinalis neurogenic bladder. ${ }^{1}$

\section{Neurofisiologi Spinal}

Pemantauan efek neurofisiologis yang ditimbulkan oleh berbagai agen anestesi selama intraoperatif sangatlah penting. Pilihan anestesi harus sesuai dengan kondisi pasien pada kasus ini yang juga disertai dengan ventrikel ekstra sistol. Pertimbangan daam memilih metode pemantauan yang tepat serta memastikan perfusi medulla spinalis tetap memadai merupakan tujuan yang paling penting karena jaringan saraf memerlukan oksigen serta nutrien-nutrien lain untuk dapat mempertahankan fungsinya. Area dengan densitas sinaptik yang tinggi akan memiliki kebutuhan oksigen yang lebih tinggi pula karena pada area tersebut juga memiliki densitas kapiler yang tinggi. Perubahan kadar oksigen dapat terjadi akibat pemberian tekanan nonfisiologis terhadap medulla spinalis, terutama gaya longitudinal atau distraksi. Pemeliharaan tekanan darah artifisial rata-rata $\geq 85 \mathrm{~mm} \mathrm{Hg}$ dan curah jantung yang memadai dapat mencegah cedera sekunder pada medulla spinalis. Atas dasar inilah, pada pasien ini dilakukan pemantauan et $\mathrm{CO}_{2}$ serta pemasangan arteri line untuk memastikan perfusi medulla spinalis tetap terjaga. Akses intravena pada pasien ini dengan kateter vena sentral juga bertujuan untuk memantau balance cairan yang memadai. ${ }^{15}$

\section{Cairan Intraoperatif}

Manajemen cairan sangat penting pada pasien dengan yang menjalani operasi tulang belakang. Akses intravena yang memadai juga sangatlah penting sehingga pada pasien ini dilakukan pemasangan akses kateter vena sentral. Pasien ini sendiri akan menjalani prosedur fusi tulang belakang bertingkat dimana durasi operasinya lama ( $>4$ jam) dan jumlah kehilangan darah yang diantisipasi kira-kira melebihi 1000 $\mathrm{mL}$, selain itu pasien juga memiliki beberapa komorbiditas. Monitoring khusus akan dilakukan pada pasien ini apabila terjadi edema paru neurogenik dan kardiogenik yang dapat diperburuk oleh pemberian cairan yang berlebih. ${ }^{1}$ Strategi tatalaksana cairan yang efektif meliputi membatasi pemberian cairan intraoperatif yang berlebihan, menghinari larutan yang mengandung glukosa, dan pemberian larutan Nacl dalam jumlah yang besar. ${ }^{15,16}$ Strategi cairan ini diterapkan dalam pemberian cairan intraoperatif pada pasien ini, yaitu ringer laktat $1500 \mathrm{ml}$, gelofusin $1000 \mathrm{ml}$, dan PRC $600 \mathrm{ml}$ dengan perkiraan pendarahan sebanyak $2000 \mathrm{ml}$ dan produksi urin intraoperatif sebanyak $500 \mathrm{ml}$. Keseimbangan asam-basa berperan penting dalam fungsi normal sel-sel tubuh. Keseimbangan asam-basa yang terganggu menandakan terjadinya dekompensasi sistem penyangga yang dapat memengaruhi fungsi neurologis dan kardiovaskular. Penggunaan $\mathrm{NaCl}$ dikaitkan dengan asidosis metabolik, dimana gangguan ini dapat dilihat dari nilai $\mathrm{HCO}_{3}$ dan defisit basa pada periode intraoperatif dan pascabedah. Asidosis dikaitkan dengan hiperkloremia, yang sering ditemui pada penggunaan infus $\mathrm{NaCl}$ volume besar. ${ }^{15,16}$ Oleh karena itu, cairan $\mathrm{NaCl}$ intraoperatif tidak digunakan pada pasien ini.

\section{Posisi Prone}

Pada kasus ini pasien diposisikan pronasi selama operasi setelah pemasangan arterial line dan kateter vena sentral. Posisi pronasi dalam kasus ini diperlukan untuk operasi tumor spinal pada tulang belakang servikal posterior sehingga dipersiapkan fasilitas meja bedah khusus, frame proning, dan aksesoris bantalan. Agar keselamatan pasien dapat terjaga selama posisi pronasi, maka terdapat beberapa hal yang perlu diperhatikan agar menghindari berbagai komplikasi (tabel 2). Komplikasi yang dapat muncul akibat posisi pronasi intraoperatif adalah nekrosis tekanan dan kerusakan otot (dengan mioglobinuria) dari 
kompresi jaringan yang lama selama operasi yang panjang, edema wajah dan jalan napas, cedera saraf perifer karena peregangan atau tekanan, kehilangan penglihatan, dan malposisi endotrakeal tube yang tidak disengaja. ${ }^{16}$

Cortical blindness merupakan salah satu post operative visual loss (POVL), yakni komplikasi yang terjadi biasanya setelah operasi tulang belakang pada posisi pronasi terjadi pada $0,013 \%$ hingga $1 \%$ kasus. Cortical blindness adalah hilangnya penglihatan dikarenakan adanya lesi bilateral pada korteks serebri lobus oksipital tanpa adanya penyebab oftalmologi dan dengan refleks pupil yang normal. Faktor penting yang berperan dalam cortical blindness yaitu hipoperfusi serebral generalisata dan embolisasi. Abnormalitas postur leher ketika posisi pasien pronasi menurunkan perfusi area vertebrobasiler sehingga dapat menyebabkan stroke. Oleh karena itu, direkomendasikan untuk menjaga leher agar tetap satu level dengan jantung atau posisi netral pada saat operasi untuk menghindari peluang terjadinya hipoperfusi karena kompresi vertebrabasillar. ${ }^{17,18}$ Dampak posisi prone terhadap kardiovaskuler yang perlu diwaspadai pada pasien ini adalah meningkatnya tahanan pembuluh darah paru dan perifer serta menurunnya aliran balik vena (venous return). Aliran balik ini akan sangat menurun terutama bila posisi kaki jauh lebih rendah dibanding posisi tubuh yang lain. Pada posisi ini terjadi pengumpulan darah (pooling) di ekstremitas bawah, sehingga diperlukan cairan kristaloid 1-2 liter sebagai kompensasi. Selain dengan pemberian cairan, pencegahan pooling dapat dilakukan dengan menggunakan stocking dan membungkus kaki sebelum pasien diposisikan pronasi. Dibandingkan posisi terlentang, volume sekuncup dan indeks kardiak akan menurun bila berada dalam posisi pronasi. ${ }^{16,17}$

\section{Ekstubasi}

Pertimbangan melakukan ekstubasi pasien ini setelah operasi tulang belakang sangat tergantung pada prosedur bedah lesi pada tingkat servikal. Pada operasi lama ( $>6$ jam) atau pasien yang memiliki edema wajah yang signifikan, akan lebih aman untuk tetap mengintubasi pasien dan menaikkan kepala tempat tidur sebesar 45 derajat.
Ekstubasi pasien kemudian akan dilakukan di ruang pemulihan atau unit perawatan intensif setelah pembengkakan wajah berkurang. ${ }^{19,20} \mathrm{Pada}$ pasien ini ekstubasi dilakukan di ruang perawatan intensif karena pembedahan berlansung selama 6 jam. Pascaoperasi pasien diobservasi di ICU dengan dukungan ventilator mekanik dan dilakukan pemantauan hemodinamik serta komplikasi pascabedah. Komplikasi pascabedah yang dapat terjadi pada operasi ini adalah cedera atau defisit neurologis, defisit volume intravaskular, anemia, koagulopati, kebocoran CSF dari robekan dural intraoperatif, hipoksemia dari atelektasis atau edema paru, atelektasis atau pneumonia, dan trombosis vena. Komplikasi khusus untuk operasi servikal anterior adalah disfagia, suara serak, dan obstruksi jalan napas akibat edema atau hematoma leher, sehingga harus dipantau selama perawatan post operatif di ICU. Pada kasus ini tidak dilakukan pemberian steroid. Pemberian steroid dapat meningkatkan resiko infeksi. Tidak ada perbedaan signifikan ditemukan antara terapi steroid dan non-steroid pada pemulangan pasien, lamanya perawatan di rumah sakit, atau komplikasi postoperasi yang lainnya. ${ }^{19,20}$

\section{Simpulan}

Operasi tulang belakang pada servikal memiliki efek kompresi medulla spinalis dapat mengakibatkan iritasi pada sistem saraf otonom. Hiperinervasi pada saraf simpatis yang berisiko tinggi pada aritmia dapat ditandai dengan hasil elektrokardiografi ventrikel ekstrasistol. Tatalaksana pada ventrikel extrasistol pemberian amiodarone dapat dipertimbangkan pada ventrikel ekstrasistol maligna yang memerlukan tatalaksana segera dengan pertimbangan hemodinamik pasien dalam keadaan stabil.

\section{Daftar Pustaka}

1. Cottrell JE, Patell P. Textbook of neuroanesthesia. New York: Elsevier; 2017. $351-98$.

2. Deiner S, Silverstein I. Anesthesia for patients with spinal cord. Anesth Spine Surg. 
$2012 ; 247-55$.

3. Lin S-Y, Hsu W-H, Lin C-C, Lin C-L, Tsai $\mathrm{C}-\mathrm{H}, \mathrm{Lin} \mathrm{C}-\mathrm{H}, \mathrm{dkk}$. Association of arrhythmia in patients with cervical spondylosis: a nationwide population-based cohort study. $\mathrm{J}$ Clin Med. 2018;7(9):236.

4. Ehab F. Anesthesia for spine surgery. Anesthesiology. 2013;119:240-1.

5. Nowicki RWA. Anaesthesia for major spinal surgery. Contin Educ Anaesthesia, Crit Care Pain. 2014;14(4):147-52.

6. O'Shaughnessy SM, Leonard I. Perioperative ventricular bigeminy and cardiomyopathy in elective surgery. Anaesth reports. 2019;7(1):53-6.

7. Sharifi G, Saedi E, Arami MA. Acute severe autonomic dysreflexia during spinal cord intramedullary tumor resectione. Iran $\mathrm{J}$ Neurosurg. 2016;1(4):27-8.

8. Rahmatisa D, Fuadi I, Sudadi S. Komplikasi autonomic dysreflexia pasca cedera medula spinalis. J Neuroanestesi Indones. 2019;8(3):207-16.

9. Marcus GM. Evaluation and management of premature ventricular complexes. Circulation. 2020;141(17):1404-18.

10. Hutchins Dan. Peri-operative cardiac arrhythmias: part two ventricular dysrhythmias anaesthesia tutorial of the week 285. World Anaesth. 2013;1-12.

11. Wongsirimeteekul P, Mai CL, Petrusa E, Minehart R, Hemingway M, Pian-Smith M, $\mathrm{dkk}$. Identifying and managing intraoperative arrhythmia: a multidisciplinary operating room team simulation case. MedEdPORTAL. $2018 ; 14$.

12. Lopshire JC, Zipes DP. Spinal cord stimulation for heart failure: preclinical studies to determine optimal stimulation parameters for clinical efficacy. J Cardiovasc Transl Res. 2014;7(3):321-9.

13. Bajwa SJS, Haldar R. Pain management following spinal surgeries: an appraisal of the available options. J craniovertebral junction spine. 2015;6(3):105.

14. Ferber J, Juniewicz H, Głogowska E, Wroński J, Abraszko R, Mierzwa J. Tramadol for postoperative analgesia in intracranial surgery. Its effect on ICP and CPP. Neurol Neurochir Pol. 2000;34(6 Suppl):70-9.

15. Kumar R, Taylor C. Cervical spine disease and anaesthesia. Anaesth Intensive Care Med. 2014;15(6):257-9.

16. Saleh SC. Sinopsis Neuroanestesi Klinik. Surabaya: Zifatama; 2013. 171.

17. Goni V, Tripathy SK, Goyal T, Tamuk T, Panda BB, Bk S. Cortical blindness following spinal surgery: very rare cause of perioperative vision loss. Asian Spine J. 2012;6(4):287

18. DePasse JM, Palumbo MA, Haque M, Eberson CP, Daniels AH. Complications associated with prone positioning in elective spinal surgery. World J Orthop. 2015;6(3):351.

19. Samartzis D, Gillis CC, Shih P, O'Toole JE, Fessler RG. Intramedullary spinal cord tumors: part I-epidemiology, pathophysiology, and diagnosis. Glob spine J. 2015;5(5):425-35.

20. Bhimani AD, Sadeh M, Esfahani DR, Arnone GD, Denyer S, Zakrzewski J, dkk. Preoperative steroids do not improve outcomes for intramedullary spinal tumors: a NSQIP analysis of 30-day reoperation and readmission rates. J Spine Surg. 2018;4(1):9. 